\title{
New inhibitors of methane production by rumen micro-organisms. Development and testing of inhibitors in vitro
}

\author{
BY J. W. CZERKAWSKI AND GRACE BRECKENRIDGE \\ The Hannah Research Institute, Ayr KA6 ${ }_{5} H L$, Scotland
}

(Received 2 fanuary 1975 - Accepted 9 May 1975)

\begin{abstract}
I. A procedure is described for assaying in vitro the activity of various inhibitors of methane production by rumen micro-organisms.

2. Methods of preparation of various inhibitors are described together with attempts to characterize these compounds by determining their physical properties (physical state, density, chromatographic behaviour), their hydrolysis by rumen contents and their relative potency as inhibitors.

3. The results of preliminary studies with trichloroethanol and its ester with pivalic acid are given.

4. The inhibitory activities of several groups of related compounds are reported. These include the polyhalogenated alcohols and their esters with pivalic acid, the esters of trihalogenated alcohols and monobasic fatty acids from $C_{2}$ to $C_{16}$ and the trihalogenated alcohol esters of dibasic acids. The results of experiments with esters of alcohols and polyhalogenated carboxylic and sulphonic acids are also given.

5. It is concluded that the mechanism of action of the inhibitors might be similar to that of known polyhalogenated methane analogues (e.g. chloroform). The relative activity of various compounds might be partly governed by the ease of their absorption into the microbial cells and by the extent to which the esters can be hydrolysed by rumen contents.

6. The results show that some substances are very poor inhibitors, unless they are esterified (e.g. trichloroacetic acid) but on the whole the esters in which the polyhalogen grouping is on the alcohol portion of the molecule are better inhibitors than those in which it is on the acid portion of the molecule.
\end{abstract}

Between 6 and $8 \%$ of the energy in the food of ruminants is converted to methane, eructed and therefore lost to the animal. It is argued that if the methane production could be inhibited specifically, rumen fermentation might change towards greater efficiency. Methane is produced from carbon dioxide and metabolic hydrogen and the manipulation could be effective if the hydrogen saved from methanogenesis could be used in formation of products that might subsequently be used by the host animal (cf. Czerkawski, 1973). The processes that are likely to require hydrogen are lipid and protein synthesis, biohydrogenation of unsaturated fatty acids and production of propionic acid in preference to acetic acid (Czerkawski, 1972; Marty \& Demeyer, 1973). Therefore, an important prerequisite in developing an inhibitor of methane production is that it will not interfere with those processes in particular and with normal metabolism of non-methanogenic micro-organisms in general.

It is also important that the inhibitor should be potent, not toxic to the host animal, easily incorporated in food (e.g. volatile compounds are not very useful) and not too expensive.

The inhibitors of methane production can be divided into two groups: alternative 
acceptors of hydrogen, and specific inhibitors of particular steps in methanogenesis. The former include the unsaturated long-chain fatty acids (see for example, Blaxter \& Czerkawski, 1966), other hydrogen acceptors such as limonene (Crane, Nelson \& Brown, 1957), sulphite (Noordam, Manten \& Muller, I949), viologen dyes (Wolin, Wolfe \& Wolin, I964) or propanediol (Czerkawski \& Breckenridge, I973). Most of these inhibitors are not very potent, and in sheep doses of $40-100 \mathrm{~g} / \mathrm{d}$ are required to give significant inhibition of methane production, but some have the advantage (e.g. unsaturated fatty acids) that they occur naturally in ruminant diets.

In the instance of long-chain fatty acids, the inhibition of methane production is not due to a simple competition for hydrogen, for although the inhibitory activity of the acids increases with unsaturation, saturated acids such as stearic and palmitic acids are also inhibitors (Blaxter \& Czerkawski, 1966). A direct demonstration of the effect of the long-chain fatty acids on pure cultures of methane bacteria was described by Prins, Van Nevel \& Demeyer (1972) and by Henderson (1973).

Bauchop ( 1967 ) found that the halogen-substituted analogues of methane, such as chloroform, are powerful inhibitors of methane production and Wood, Kennedy \& Wolfe ( 1968 ) found that the activity is probably due to formation of halogen analogues of methylcyanocobalamin from reduced cyanocobalamin. Many related substances were subsequently found to be strong inhibitors of methane production. Rufener $\&$ Wolin (1968) used carbon tetrachloride, Singh \& Trei (1971), Johnson, Wood, Store \& Morgan (1972) and Sawyer, Hoover \& Sniffen (1974) used bromochloromethane. Johnson (1972) and Trei, Scott \& Parish (1972) used a hemi-acetal of chloral (trichloroacetaldehyde) and starch. McBride \& Wolfe (1971) showed that DDT was a potent inhibitor of methanogenesis.

The advantage of using compounds such as chloral (Van Nevel, Henderickx, Demeyer \& Martin, 1969) or trichloroacetamide (Trei, Parish, Singh \& Scott, 1971) is their non-volatility compared with chloroform or bromochloromethane.

Following the successful use of long-chain fatty acids to inhibit methane production (Czerkawski, Blaxter \& Wainman, I966; Demeyer \& Henderickx, 1967) further work (Clapperton \& Czerkawski, 1971) showed that some tertiary fatty acids with more than ten carbon atoms (the versatic acids) were more active as methane inhibitors than the straight-chain fatty acids. It seemed worthwhile to try and combine the properties of these acids and polyhalogen compounds in single substances. This was the primary objective, but, as will be seen subsequently, in the course of the present work many other compounds have been synthesized, tested and shown to be even more interesting.

\section{EXPERIMENTAL}

\section{Assay of inhibitory activity in vitro}

The inhibitory activity of various compounds was determined by incubation of rumen contents in a modification of a small-scale artificial rumen, essentially as described by Czerkawski \& Breckenridge (1970).

The samples of rumen contents were taken before the morning feed from sheep that were provided with rumen fistulas and given $500 \mathrm{~g}$ molassed sugar-beet pulp at 
09.00 hours and $35^{\circ} \mathrm{g}$ hay at 17.00 hours. The rumen contents were strained through four layers of gauze and used within $30 \mathrm{~min}$.

Samples of rumen contents $(20 \mathrm{ml})$ were introduced into $50 \mathrm{ml}$ glass syringes provided with three-way plastic taps. To each syringe was then added $\mathrm{I} \cdot \circ \mathrm{ml}$ of a solution containing $5 \circ \mathrm{mg}$ glucose, followed by $4.0 \mathrm{ml}$ of a test solution containing the inhibitor emulsified in Tween 80 (Honeywill \& Stein Ltd, London $\mathrm{W}_{\mathrm{I}}$ ) solution ( $\mathrm{r} \mathrm{g} / \mathrm{l})$. Some air bubbles that inevitably collected in the syringes were expelled and $5 \mathrm{ml}$ carbon dioxide-nitrogen $(5: 95, \mathrm{v} / \mathrm{v})$ was introduced into each syringe. With each series of incubations at least two controls were set up with $4 \mathrm{ml}$ Tween 80 solution. The contents in the syringes were mixed gently by inversion and the syringes were incubated in a water bath at $39^{\circ}$ for 4 or $5 \mathrm{~h}$, the contents being mixed intermittently throughout the incubation. At the end of incubation the gas was transferred to a $20 \mathrm{ml}$ glass syringe that was wetted with water, and the volume of gas was noted. The gas was analysed chromatographically as described by Czerkawski \& Clapperton (I968) and the volumes of methane, hydrogen and carbon dioxide were calculated.

In most experiments at least three levels of inhibitor were tested to obtain between 20 and $80 \%$ inhibition, and the amount of inhibitor required to give $50 \%$ inhibition was calculated by interpolation. In some experiments the liquid samples at the end of incubation were used for the determination of the concentration of volatile fatty acids by the method of Cottyn \& Boucque (1968).

\section{Hydrolysis of esters}

The extent of hydrolysis of esters was determined using rumen contents as described in the assay of inhibitory activity, but the concentration of inhibitor was much greater. Samples of rumen contents $(8 \mathrm{ml})$ were pipetted into glass-stoppered testtubes. To each was added $\mathrm{I} \mathrm{ml}$ water containing $25 \mathrm{mg}$ glucose, and $\mathrm{I} \mathrm{ml}$ Tween 80 solution ( $\mathrm{o} \circ \mathrm{g} / \mathrm{l}$ ) containing $0.3 \mathrm{mmol}$ ester. Tween 80 solution without ester was added to control tubes. Carbon dioxide-nitrogen $(5: 95, \mathrm{v} / \mathrm{v})$ was bubbled through the contents of each tube. The tubes were then stoppered loosely and incubated at $39^{\circ}$ for 2 or $5 \mathrm{~h}$, during which time they were shaken at intervals. After incubation, portions $(4 \mathrm{ml})$ of reaction mixtures were treated with $\mathrm{I} \mathrm{ml}$ precipitating agent (Cottyn \& Boucque, 1968), allowed to stand for $30 \mathrm{~min}$ and centrifuged. The amounts of products of hydrolysis were analysed using gas-liquid chromatography (GLC) (see p. 433).

\section{Materials}

Many compounds were synthesized; the following compounds were purchased: 2-chloroethanol, pentan-I-ol, benzoyl chloride, trichloroacetyl chloride, from BDH Ltd, Poole, Dorset; trichloroacetone, oxalyl chloride, hexachloroacetone, I, I,Itrichloro-2-propanol, I,I,I-trichloro-2-methyl-2-propanol hydrate, 2,2-dichloroethanol, 2,2,2-trichloroethanol (TCE), 2,2,2-trifluoroethanol, 2,2,2-tribromoethanol, 4-methyl-r-pentanol, neopentyl alcohol, I,6-hexanediol, methane sulphonyl chloride, glutaryl dichloride, isobutyryl chloride, isovaleryl chloride, from Ralph N. Emanuel Ltd, Wembley, Middx.; $p$-toluene sulphonyl chloride, trichloromethane sulphonyl 
chloride, pivaloyl chloride, from Koch-Light Laboratories Ltd, Colnbrook, Bucks.; adipoyl chloride, from Hopkin and Williams, Romford, Essex. Isobutyraldehyde and 2,5-hexanediol were kindly given by Ralph N. Emanuel Ltd, Wembley, Middx.

\section{Preparation of esters}

If possible the acid chlorides were obtained commercially and used as starting materials for the preparation of esters. Occasionally the acid chlorides were prepared by treating the acids with about five times their weight of oxalyl chloride and allowing to stand for $2 \mathrm{~d}$. The excess oxalyl chloride was removed at room temperature using a rotary evaporator. The alcohols were added gradually to the acid chlorides until the alcohol was $20-30 \%$ in excess of the amount required for complete reaction (with dihydroxy alcohols, an excess of acid chloride was used). The mixtures were allowed to stand for $\mathrm{I}-2 \mathrm{~h}$, heated at $70^{\circ}$ under reflux for $\mathrm{I} h$ and then allowed to stand overnight. The heating was not necessary with some compounds. The reaction mixtures were treated with dilute sodium hydroxide to neutralize the acid and decompose the unreacted acid chloride and then washed repeatedly with water in a separating funnel or a centrifuge tube to remove the unreacted acid and alcohol. When the ester was a solid at room temperature, after the initial treatment with sodium hydroxide solution, the ester was dissolved in $n$-hexane and purified in the usual manner. Occasionally, when it was difficult to remove the alcohol completely by the method described, the samples $(\mathrm{I}-2 \mathrm{~g})$ were applied to columns $(20 \times 400 \mathrm{~mm})$ of Florisil (60-I00 mesh; BDH Chemicals, Poole, Dorset) and eluted with $n$-hexane or with increasing concentrations of diethyl ether in $n$-hexane, leaving the alcohol on the column. Sometimes large amounts of esters had to be prepared and the procedure had to be modified. Trichloroethyl adipate (TCE-A) was a solid at room temperature. In a typical preparation a reaction mixture of $100 \mathrm{ml}$ adipoyl chloride and $200 \mathrm{ml} \mathrm{TCE}$, after standing for $24 \mathrm{~h}$, was treated with $n$-hexane $(300-400 \mathrm{ml})$ and extracted once with water, then extracted repeatedly with $0 \cdot 1 \mathrm{M}$-sodium hydroxide, until the extracts were alkaline, and then finally with water. The $n$-hexane was evaporated using a rotary evaporator to give about $280 \mathrm{~g}$ residue which was impure TCE-A, containing some TCE and some brown-coloured material. It was purified further by melting, dissolving in 2 vol. ethanol-water $(95: 5, \mathrm{v} / \mathrm{v})$ (industrial spirit) at $50^{\circ}$, cooling to below $10^{\circ}$, and allowing the product to crystallize with stirring. The crystals were filtered using a Buchner funnel, dried and recrystallized twice more to give about $220 \mathrm{~g}$ white, odourless crystals that were chromatographically pure (about $75 \%$ yield).

\section{Characterization of compounds}

The esters were characterized by determining their melting or boiling points, their density and their behaviour on GLC. It was assumed that a new single peak with a retention volume different from that of the constituent acid and alcohol was due to the prepared ester. This was usually confirmed by hydrolysing the ester in alkali and analysing the products.

GLC was done using a gas-liquid chromatograph (Model no. 104; Pye Unicam Ltd, 
Cambridge) with $\mathrm{r} \cdot 5 \times 5 \mathrm{~mm}$ columns of $50 \mathrm{~g}$ Carbowax $20 \mathrm{M} \mathrm{TPA} / \mathrm{kg}$ Chromosorb G (Perkin-Elmer Ltd, Beaconsfield, Bucks.) at 100,140 or $155^{\circ}$, or with $1.5 \times 5 \mathrm{~mm}$ columns of $150 \mathrm{~g}$ ethylene glycol succinate (EGS-X)/kg Gas-chrom P (Field Instruments Co. Ltd, Richmond, Surrey) at 120 or $190^{\circ}$. A flame-ionization detector (PyeUnicam Ltd) was used and the peak areas were measured with a disc integrator (Disc Instruments Ltd, Hemel Hempstead, Herts.), mounted on a Speedomax W recorder (Leeds \& Northrup, Birmingham). Sometimes, when the compounds were not sufficiently volatile or when they tended to decompose on GLC, they were analysed by thin-layer chromatography (TLC) by Dr W. W. Christie of this Institute.

The relative retention times of most of the compounds tested are summarized in Table I; the relative retention times of common compounds are also given for comparison. The TCE esters of monobasic and dibasic acids were well separated, as well as the trichloroacetic acid (TCA) esters of mono- and dihydric alcohols. The TCA ester of 2,5-hexanediol gave two peaks of approximately equal area. This compound migrated as one spot on TLC, fractionally faster than the TCA ester of $\mathrm{I}, 6$-hexanediol, which gave a single peak on GLC. It was concluded that the preparation contained a mixture of stereoisomers, with a large proportion of the meso-compound.

Solubility in water. The solubility of some other compounds in water at room temperature was determined by adding an excess of ester at $30^{\circ}$, cooling to room temperature, centrifuging, concentrating a portion of the supernatant fraction and determining the amount dissolved using GLC. In some instances the ester had to be hydrolysed and the alcohol determined.

TCE pivalate (TCE-P) was slightly soluble in water $\left(32 \mathrm{mg} / 1\right.$ at $\left.20^{\circ}\right)$, whereas the solubility of tribromoethyl pivalate was much less $(0.05 \mathrm{mg} / \mathrm{l})$. The solubility of TCE succinate was $5.7 \mathrm{mg} / \mathrm{l}$ and that of TCE-A was less than $0.5 \mathrm{mg} / \mathrm{l}$. The solubility of tribromoethyl adipate appeared to be less than $0.1 \mathrm{mg} / \mathrm{l}$.

\section{RESULTS}

\section{Preliminary studies with TCE-P}

Comparison of inhibitory activity of TCE-P and its constituents. Clapperton \& Czerkawski ( I97I) have shown that pivalic acid does not inhibit methane production, whereas TCE is a strong inhibitor. An example of a dose-response curve obtained with this compound is shown in Fig. I. Clearly the response was not linear; it was rapid with small concentrations of inhibitor. Hydrogen gas accumulated in proportion to inhibition of methane production at about $\mathrm{I} \cdot 4 \mathrm{~mol} / \mathrm{mol}$ methane. Other similar experiments showed that when the concentrations of inhibitor were increased further, the apparent methane production remained at about $25 \mu \mathrm{l} / \mathrm{h}$ per $20 \mathrm{ml}$ rumen contents, the accumulation of hydrogen increased further and then began to decrease. We concluded that the apparent methane production in the presence of high concentrations of inhibitor was due to methane that was in solution in rumen contents at the start of incubation. The decrease in accumulation of hydrogen at high concentrations of inhibitor suggested that at these concentrations the inhibitor began to interfere with general fermentation. The accumulation of hydrogen reached a maxi- 


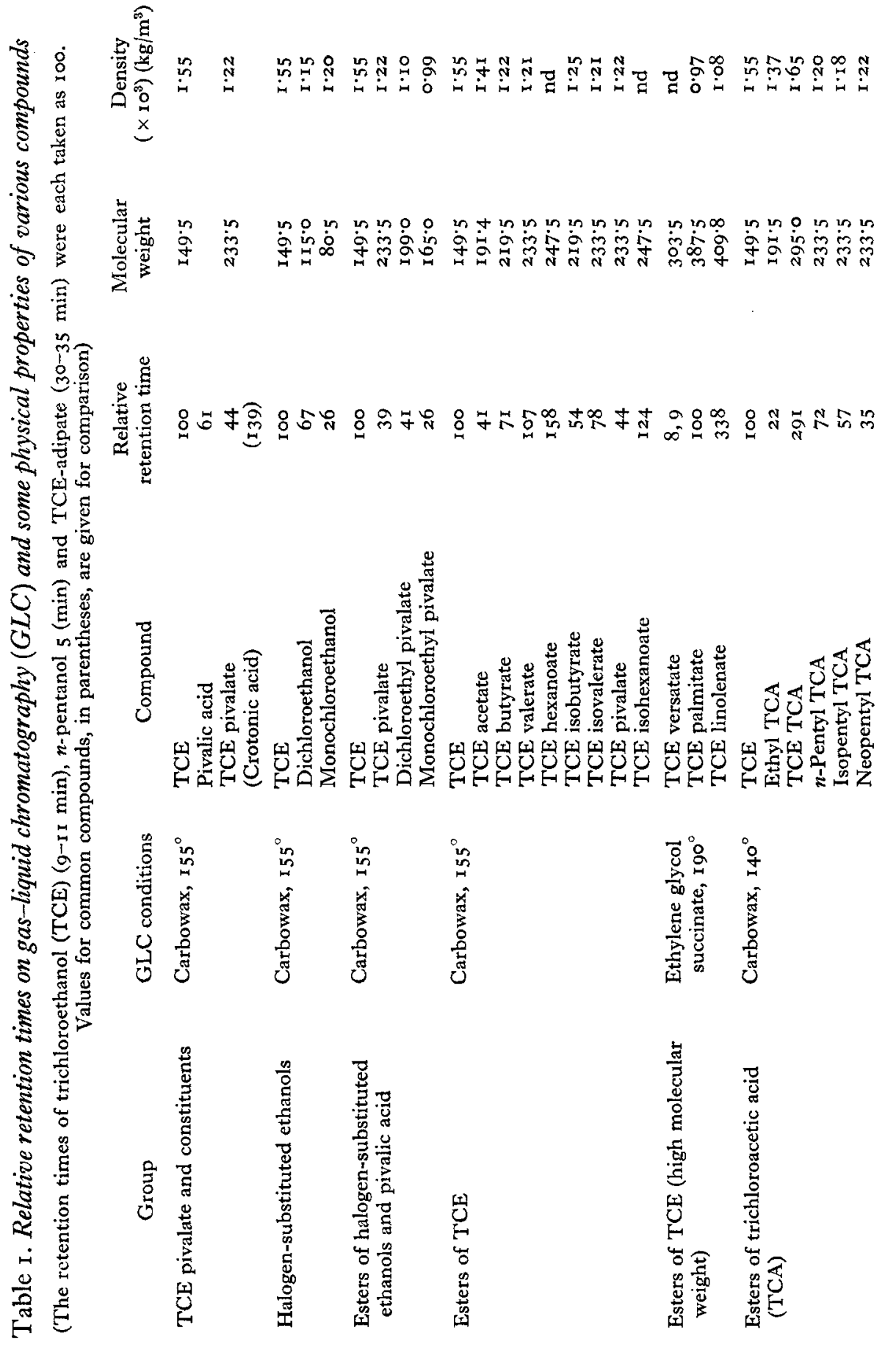




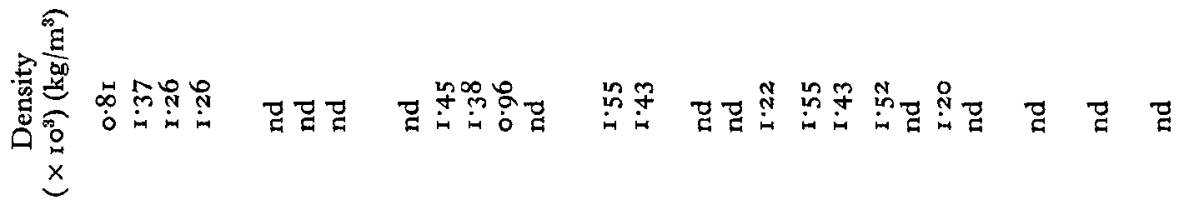

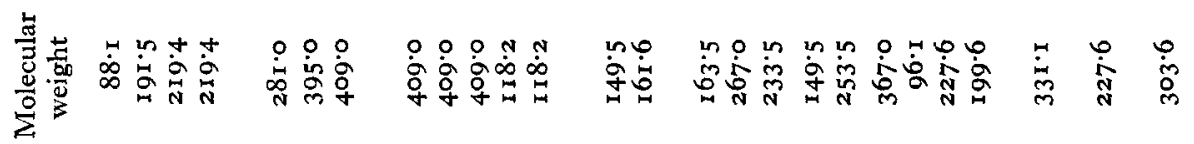

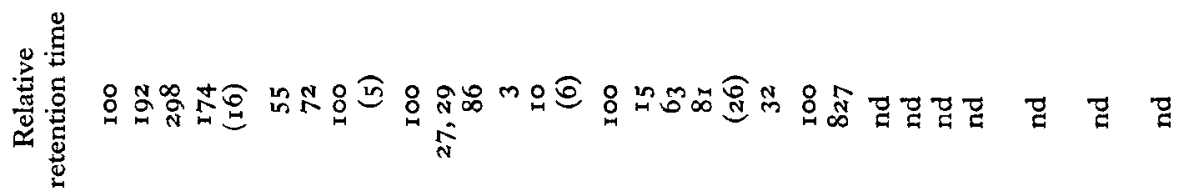

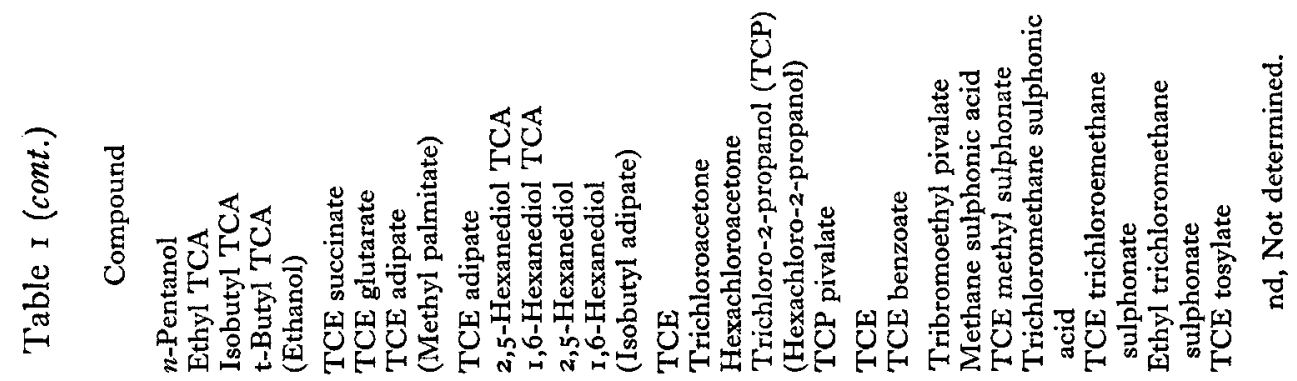

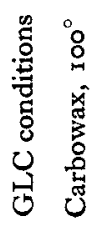

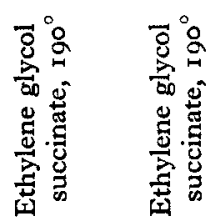

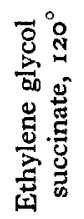

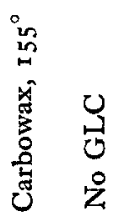

茪

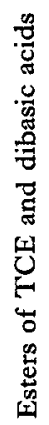

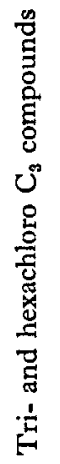

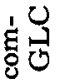

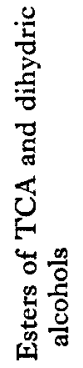

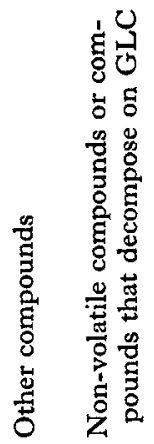




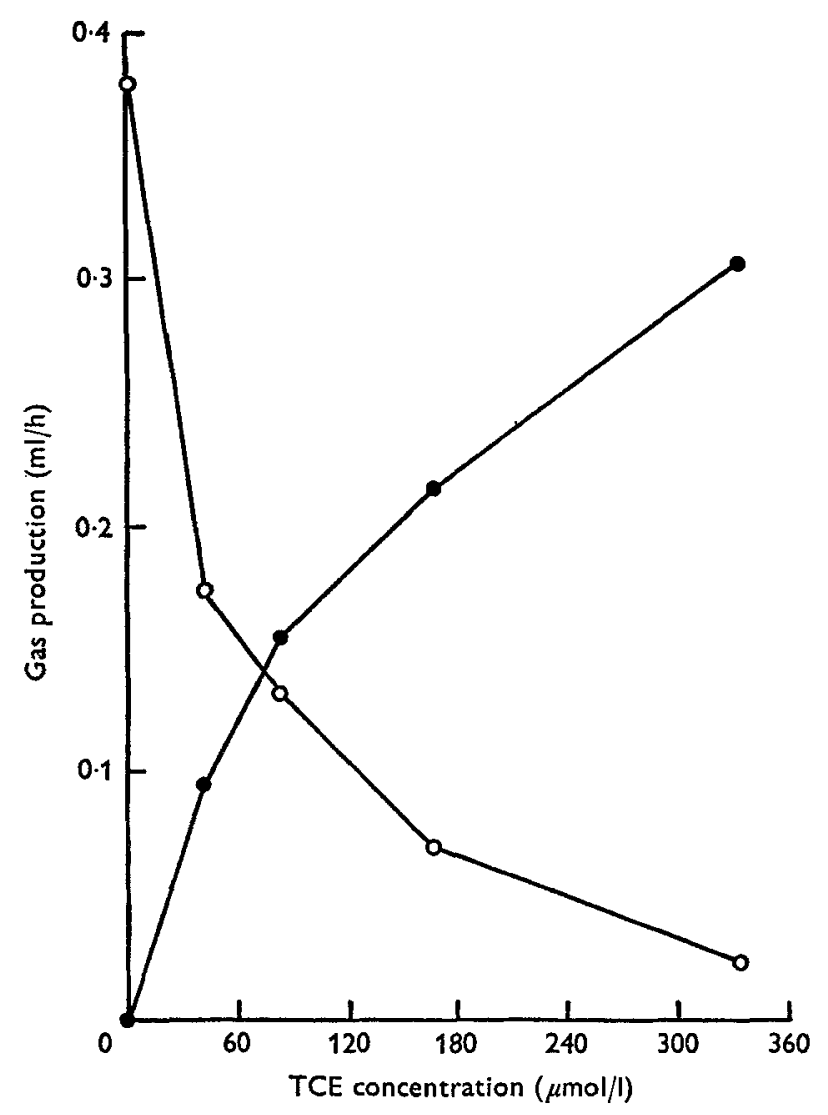

Fig. I. Production of methane and hydrogen during incubation of sheep rumen contents in vitro with increasing amounts of trichloroethanol (TCE) under standard conditions (see pp. 430-1); O-O, methane;

- hydrogen.

mum at higher concentrations of inhibitor than were necessary for nearly complete inhibition of methane production. Therefore it appears that the inhibitor is specific in reasonable concentration. Experiments like those shown in Fig. I showed that TCE-P was as active as TCE. It is unlikely that the ester is hydrolysed instantaneously (see p. 437) and these results indicated that the ester itself might inhibit methane production. It is possible to estimate by interpolation the amounts of inhibitor required to give $50 \%$ inhibition. When experiments were done on different occasions the amounts of inhibitor required to give $50 \%$ inhibition varied, although the same sheep on a constant feeding regimen were used as donors of rumen contents. This variation was unavoidable and difficult to explain and, therefore, during subsequent development and testing of various inhibitors a positive control of TCE-P was included with every series of incubations. The amounts used gave $40-60 \%$ inhibition of methane production. The results of these control incubations for two particular sheep are shown in Fig. 2. There was no difference between sheep, and the supplementation of the rations with minerals (particularly cobalt) did not appear to have any effect. A sample of TCE-P, stored in the dark at $5^{\circ}$, was used in most of these assays, but after 3 and 6 


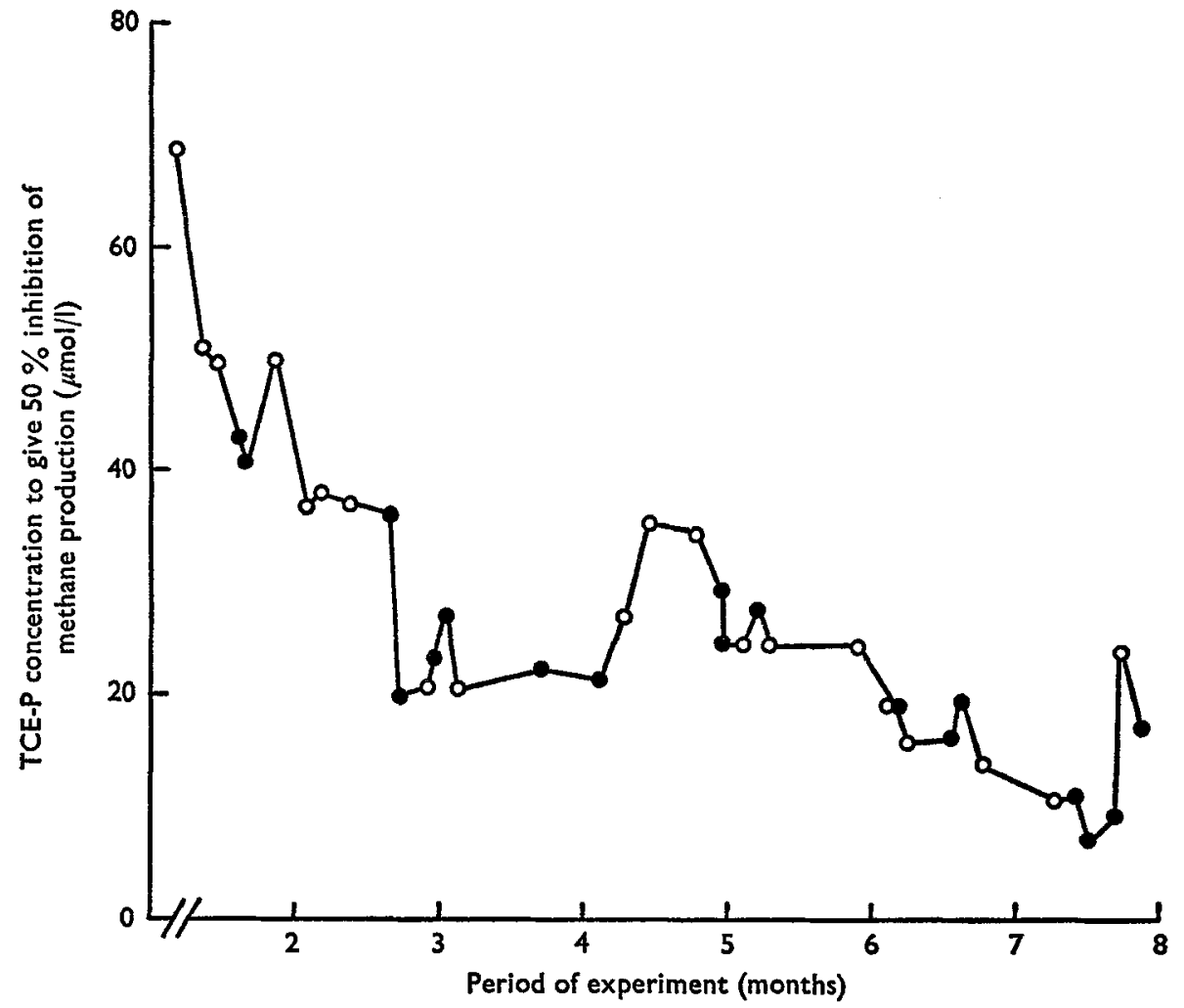

Fig. 2. Concentration of trichlorocthyl pivalate (TCE-P) required to give $50 \%$ inhibition of methane production during incubation, under standard conditions (see pp. 430-r), of samples of rumen contents taken from two sheep that were given a constant diet of molassed sugar-beet pulp and hay for a period of about 8 months. - Sheep, $564 ; 0-0$, sheep 565 .

months of storage, new samples of TCE-P were prepared and tested at the same time as the old sample. There was no difference in inhibitory activity, and it was concluded that the tenfold increase in potency of the inhibitor over 6-7 months, was not due to formation of a strong inhibitor fragment, but related to changes in the composition of rumen contents.

Hydrolysis of TCE-P during incubations with rumen contents. The inhibitory concentrations of TCE-P were very low (ro-roo $\mu \mathrm{mol} / 1$ ) and it was impossible to measure the extent of hydrolysis at these concentrations with the analytical techniques available. However, several experiments were done in which the concentration of inhibitor was much greater ( $\mathrm{I}-2 \mathrm{mmol} / \mathrm{l})$. Under these conditions it was possible to measure the disappearance of the ester and the formation of the acid and alcohol.

Using undiluted rumen contents and $I_{4} 4 \mathrm{~mm}-\mathrm{TCE}-\mathrm{P}$, the concentration of the ester decreased rapidly at first $(0.6 \mathrm{mmol} / \mathrm{l}$ per $\mathrm{h})$ and then more slowly. After incubation for $5 \mathrm{~h}$ about $25 \%$ of the substrate remained. Pivalic acid and TCE were produced in approximately stoichiometric amounts. When increasing concentrations of TCE-P ( $\mathrm{I}-6 \mathrm{mmol} / 1$ ) were incubated with undiluted rumen contents for $2 \mathrm{~h}$, there was only a slight increase in hydrolysis with increasing substrate concentrations, the mean 
Table 2. Effect of the number and type of halogen atoms in halogen-substituted ethanols and their pivalate esters on the inhibition of methane production during incubation of sheep rumen contents in vitro*

(Mean values; no. of incubations in parentheses)

\begin{tabular}{|c|c|c|c|c|}
\hline \multirow[b]{2}{*}{ Halogen compound } & \multicolumn{2}{|c|}{$\begin{array}{l}\text { Concentration to give } 50 \% \\
\text { inhibition }(\mu \mathrm{mol} / 1)\end{array}$} & \multicolumn{2}{|c|}{$\begin{array}{l}\text { Maximum concentration } \\
\text { tested (mmol/l) }\end{array}$} \\
\hline & Alcohol & Pivalate & Alcohol & Pivalate \\
\hline Monochloroethanol & $45900(2)$ & $-\dagger(2)$ & $47 \cdot 5$ & $23 \cdot 0$ \\
\hline Dichloroethanol & I700 (2) & $575^{\circ}(2)$ & $2 \cdot 5$ & II.4 4 \\
\hline Trichloroethanol & $4 \mathrm{I}(4)$ & $37(4)$ & $-\ddagger$ & $-\ddagger$ \\
\hline Trifluoroethanol & $-\dagger(2)$ & $29300(2)$ & I 3.9 & $35 \cdot 9$ \\
\hline Tribromoethanol & $3(3)$ & $r_{3}(3)$ & -1 & $-t$ \\
\hline
\end{tabular}

values for the whole range were $(\mathrm{mmol} / \mathrm{l} \mathrm{per} h)$ : disappearance of TCE-P 0.45 , production of pivalic acid 0.50 , production of TCE 0.47 . It was impossible to see whether this rate would decrease when the concentrations became similar to those used for inhibition studies.

When rumen contents were diluted with cell-free rumen fluid and incubated with $3 \mathrm{mM}$-TCE-P for up to $2 \mathrm{~h}$, with an inoculum concentration of less than $0.5 \mathrm{ml} / \mathrm{ml}$, the disappearance of TCE-P and the appearance of the alcohol and acid were proportional to the concentration of rumen contents. With an inoculum concentration greater than $0.5 \mathrm{ml} / \mathrm{ml}$, the rates were independent of concentration of rumen contents and remained at about $0.55 \mathrm{mmol} / \mathrm{l}$ per $\mathrm{h}$.

These results suggest that intact TCE-P might be an active inhibitor of methane production, but they do not exclude the possibility that the hydrolysis might be very rapid at low concentrations of the ester and that the active component is the free alcohol.

\section{Halogen-substituted ethanol and its esters}

Alcohols and esters of pivalic acid. Two series of experiments were done: (I) the effect of the number of chlorine atoms in the alcohol on methane production was studied, (2) the effect of the type of halogen was studied. In each instance several levels of inhibitor were tested to determine amounts that would give $40-60 \%$ inhibition. Subsequently the esters were tested at the same time as the corresponding alcohol, and the concentrations required to give $50 \%$ inhibition were calculated, if possible by assuming an exponential function of inhibitor concentration. The results of these experiments are summarized in Table 2. Monochloroethanol was a very weak inhibitor and its ester with pivalic acid was non-inhibitory at the levels tested. The disubstituted alcohol was moderately inhibitory, but its pivalate ester was much weaker. TCE, as found already in preliminary studies, was a potent inhibitor. TCE-P was marginally, but consistently, a stronger inhibitor than the alcohol. Trifluoroethanol did not inhibit methane production at the concentrations tested and its ester with 
Table 3. Inhibition of methane production during incubation of sheep rumen contents in vitro with trichloroethyl esters of fatty acids, and hydrolysis of esters by rumen contents*

(All values, except where indicated, are results of a single comparative experiment)

Ester of:

Acetic acidt

Butyric acid

Isobutyric acid

Valeric acid

Isovaleric acid

Pivalic acid

Hexanoic acid

Isohexanoic acid

Palmitic acid $\dagger$

Versatic acid + t

Linolenic acidt

\section{Concentration to give $50 \%$} inhibition $(\mu \mathrm{mol} / \mathrm{l})$

$19 \cdot 2(9 \cdot 7)$
$27 \cdot 5$
$30 \cdot 2$
$20 \cdot 7$
$25 \cdot 4$
$25 \cdot 6$
$21 \cdot 3$
$41 \cdot 4$
$163(45)$
$242(52)$
$980(50)$

$27 \cdot 5$

$25 \cdot 4$

$25 \cdot 6$

$4 \mathrm{I} \cdot 4$

$242(52)$

$980(50)$

Rate of hydrolysis under

standard conditions*

$(\mathrm{mmol} / \mathrm{mol}$ per $\mathrm{h}$ )

$>250$
157
171
288
45
15
250
251
8
$<1$
nd

nd, Not determined.

* For details of experimental procedures, see p. $43 \mathrm{I}$.

+ Separate determinations; the values in parentheses refer to trichloroethyl pivalate determined at the same time.

$\ddagger$ A tertiary $C_{10}$ fatty acid with at least one methyl group on the $\alpha-C$ atom.

pivalic acid was only weakly inhibitory. Tribromoethanol was the most potent inhibitor. Tribromoethyl pivalate was less active, but it was considerably more active than TCE and its ester. As will be seen later, when other inhibitors are considered, TCE was unusual in that its ester with pivalic acid was consistently as active as the free alcohol and sometimes more active.

$T C E$ esters of monobasic fatty acids. After preparation and purification, each compound was tested at several concentrations to determine the concentration required to give $50 \%$ inhibition of methane production under standard conditions. The amounts required were calculated by interpolation. When the complete series of compounds was available, they were tested simultaneously using the single concentrations calculated to give about $50 \%$ inhibition, and the actual amounts required to give $50 \%$ inhibition were calculated by assuming an exponential law. The two sets of results were similar and the mean values are given in Table 3 . In general, the inhibitory activity was maximal with the $\mathrm{C}_{5}$ fatty acids of both the straight-chain and the iso-series, although the differences between the straight-chain and the iso-series were small with $\mathrm{C}_{4}$ and $\mathrm{C}_{5}$ compounds and increased with $\mathrm{C}_{6}$ fatty acids. The inhibition was less with the TCE esters of palmitic acid and versatic acid, a tertiary $\mathrm{C}_{\mathbf{1 0}}$ carboxylic acid with at least one methyl group on the $\alpha-\mathrm{C}$ atom. Linolenate, the longest-chain acid used, was a very weak inhibitor. Although pivalic acid is a heavily branched isomer of valeric acid, TCE-P did not follow the trends shown by the esters of the other acids. The results of the determination of the extent of hydrolysis of the esters are also shown in Table 3. All the straight-chain compounds were hydrolysed relatively rapidly, while TCE isovalerate was hydrolysed more slowly than the TCE esters of isobutyric and isohexanoic acids; TCE-P had the slowest rate of hydrolysis. 
Table 4. Inhibition of methane production during incubation of sheep rumen contents in vitro with esters of dibasic acids, and hydrolysis of esters by rumen contents*

(The values in parentheses are those for trichloroethyl pivalate determined at the same time)

\begin{tabular}{|c|c|c|c|c|}
\hline \multirow[b]{3}{*}{ Compound } & \multicolumn{3}{|c|}{$\begin{array}{l}\text { Concentration to give } 50 \% \text { inhibition } \\
\qquad(\mu \mathrm{mol} / 1)\end{array}$} & \multirow{3}{*}{$\begin{array}{l}\text { Rate of hydrolysis } \\
\text { under standard } \\
\text { conditions* } \\
(\mathrm{mmol} / \mathrm{mol} \mathrm{per} \mathrm{h})\end{array}$} \\
\hline & \multirow{2}{*}{$\begin{array}{l}\text { Individual } \\
\text { estimations }\end{array}$} & \multicolumn{2}{|c|}{$\begin{array}{l}\text { Comparative } \\
\text { experiments }\end{array}$} & \\
\hline & & $a$ & $b$ & \\
\hline oroethyl succinate & $22 \cdot 7(27)$ & $\mathrm{x} 8 \cdot 9$ & $20 \cdot 6$ & 80 \\
\hline oroethyl glutarate & $18.6(20)$ & 10.0 & 4.9 & 28 \\
\hline oroethyl adipate & $69.0(53)$ & 9.5 & 6.5 & 36 \\
\hline moethyl succinate & $4 \cdot 3(27)$ & nd & nd & nd \\
\hline moethyl adipate & $10.3(27)$ & nd & nd & nd \\
\hline$y l$ adipate & $1930(25)$ & nd & nd & nd \\
\hline oroethanol & $45^{\circ} \cdot(53)$ & $33 \cdot x$ & nd & - \\
\hline moethanol & $4.5(25)$ & 6.1 & nd & $\ldots$ \\
\hline oroethyl pivalate & - & $20 \cdot 0$ & $17 \cdot 0$ & 15 \\
\hline
\end{tabular}

nd, Not determined.

* For details of experimental procedures, see p. $43 \mathrm{I}$.

+ Results of two experiments in which the compounds were incubated concurrently with rumen contents. The test concentrations of the compounds were chosen to give about $50 \%$ inhibition.

It is possible that this was due to steric hindrance brought about by the three methyl groups in close proximity to the ester bond, and this supports the hypothesis that TCE-P acts in the ester form as an inhibitor of methane production.

Esters of dibasic acids. The inhibitory activity of esters of dibasic acids is given in Table 4. Since each ester of a dibasic acid has two active groups, to compare their activity with the other compounds one might have to double the values given in Table 4. The most active ester was that of tribromoethanol, but it was not as active as the alcohol itself. With the trichloro-substituted esters, the succinate ester was less active than the adipate or glutarate esters and the activity was parallelled by the extent of hydrolysis. Isobutyl adipate was a weak inhibitor.

\section{Comparison of alcohol- and acid-substituted halogen compounds}

Esters of TCA. Although the amide of TCA is a strong inhibitor of methane production (Trei et al. 1971), TCA itself is a very weak inhibitor. In the course of present work several TCA esters were prepared and tested. The results, together with those of some constituents of the esters, and other substances of interest, are summarized in Table 5. In general, TCA esters were more active than TCA itself; the TCA ester with TCE was a good inhibitor but the esters of TCA and the non-chlorinated alcohols were weaker. Generally the activity of the esters increased with the increased branching of the alcohol part of the ester. It is possible that the ethyl ester was losing its activity because of hydrolysis to inactive or weakly active products and that the branched compounds were less easily hydrolysed and therefore more active.

The effect of branching in the isomers of $\mathrm{C}_{5}$ alcohols esterified with TCA can also be seen in Table 5. These esters were isomers of TCE-P but even the most active one, 
Table 5. Inhibition of methane production during incubation of sheep rumen contents in vitro with the esters of trichloroacetic acid (TCA) and related compounds and hydrolysis of esters by rumen contents*

(For individual estimations the values in parentheses are those for the trichloroethanol (TCE) ester of pivalic acid incubated with rumen contents at the same time)

\begin{tabular}{|c|c|c|c|}
\hline \multirow[b]{2}{*}{ Compound } & \multicolumn{2}{|c|}{$\begin{array}{c}\text { Concentration to give } 50 \% \\
\text { inhibition }(\mu \mathrm{mol} / 1)\end{array}$} & \multirow{2}{*}{$\begin{array}{l}\text { Rate of hydrolysis } \\
\text { under standard } \\
\text { conditions* } \\
\text { (mol/mol per h) }\end{array}$} \\
\hline & $\begin{array}{l}\text { Individual } \\
\text { estimations }\end{array}$ & $\begin{array}{l}\text { Comparative } \\
\text { experiment† }\end{array}$ & \\
\hline TCA & $3300(\mathrm{I} 6)$ & $3^{890}$ & - \\
\hline TCE & $27(26)$ & nd & - \\
\hline TCE TCA ester & $22(16)$ & nd & nd \\
\hline Ethyl TCA & $773(26)$ & 1750 & 7500 \\
\hline Isobutyl TCA & 344 (I6) & 717 & 196 \\
\hline t-Butyl TCA & $140(16)$ & 257 & nd \\
\hline n-Pentyl TCA & $846(7)$ & nd & 136 \\
\hline Amyl TCA & $48 I(7)$ & nd & 90 \\
\hline Neopentyl TCA & $307(7)$ & nd & 56 \\
\hline TCA 2,6-hexanediol & $695(30)$ & nd & nd \\
\hline TCA I,6-hexanediol & $710(30)$ & nd & nd \\
\hline Isobutyl isobutyrate & $24100(26)$ & nd & nd \\
\hline Isobutyraldehyde & $25700(26)$ & nd & nd \\
\hline TCE adipate & $5(6)$ & nd & 26 \\
\hline TCE pivalate & - & $2 I$ & I 5 \\
\hline
\end{tabular}

nd, Not determined.

* For details of experimental procedures, see p. $43 \mathrm{I}$.

$\dagger$ All compounds were tested concurrently, using concentrations that would give about $50 \%$ inhibition.

neopentyl TCA, was about forty times weaker than TCE-P. The fact that compounds with the trichloro group on the alcohol residue are better inhibitors than those with the trichloro group on the acid residue is supported by results for two other isomeric esters given in Table 5. Clearly, TCE adipate was about 130 times more active than TCA hexanediol.

The results of earlier work indicated that isobutanol was not an inhibitor of methane production (Czerkawski \& Breckenridge, I972), and the results summarized in Table 7 show that both isobutyl isobutyrate and isobutyraldehyde are very weak inhibitors. Isobutyric acid occurs naturally in the rumen.

Normally, TCA did not inhibit methane production to any great extent, but occasionally it became more potent and this was shown subsequently to be due to some changes brought about by storage. The results of a typical experiment to illustrate this was shown in Table 6. Clearly, when solutions of the sodium salt of TCA were kept for I9 $\mathrm{d}$ there was an eightfold increase in inhibitory activity and this was increased further when TCA solutions were stored in the presence of Tween 80. The latter could have been due to transesterification with the detergent, but the mechanism of the former is unknown. It could have been due to slow cleavage to chloroform and sodium bicarbonate. Chloroform is a potent inhibitor and the conversion of only $2 \%$ of the TCA to chloroform would have resulted in the increase found in inhibitory activity. 
Table 6. Increase in the inhibitory activity of trichloroacetic acid (TCA) with respect to methane production during incubation of sheep rumen contents in vitro*, after storage, with or without Tween 80 , in aqueous solution $(2.5 \mathrm{mg} / \mathrm{ml}$, neutralized with sodium hydroxide) in the dark at room temperature for 7 or $19 d$

(The values are expressed as relative inhibitory activity, i.e. the activity relative to that of tricholoroethyl pivalate (1000) tested at the same time; all samples were tested at a concentration to give approximately $50 \%$ inhibition)

\begin{tabular}{|c|c|c|c|c|c|}
\hline \multirow[b]{3}{*}{$\begin{array}{l}\text { Amount used/incubation } \\
\text { vessel }(\mathrm{mg})\end{array}$} & \multirow{2}{*}{\multicolumn{2}{|c|}{$\begin{array}{l}\text { Period of storage } \\
\text { (d) }\end{array}$}} & \\
\hline & & & & $\begin{array}{c}\text { Increment } \\
\text { due to }\end{array}$ & \\
\hline & $\begin{array}{l}\text { TCA } \\
\text { alone }\end{array}$ & $\begin{array}{l}\text { TCA+ } \\
\text { Tween } 80\end{array}$ & $\begin{array}{l}\text { Total } \\
\text { measured }\end{array}$ & $\begin{array}{l}\text { storage ot } \\
\text { TCA and } \\
\text { Tween } 80\end{array}$ & $\begin{array}{l}\text { Increment } \\
\text { due to } \\
\text { Tween } 80\end{array}$ \\
\hline 10.0 & 0 & 0 & $6 \cdot 9$ & - & - \\
\hline $1 \cdot 25$ & 19 & 0 & $57^{\prime} \mathrm{I}$ & $50 \cdot 2$ & - \\
\hline 10.0 & 0 & 0 & $7 \cdot 8$ & - & - \\
\hline I' 25 & 19 & $\circ$ & $42 \cdot 1$ & $34 \cdot 3$ & $\ldots$ \\
\hline$I \cdot 25$ & 19 & 7 & $64 \cdot 4$ & $56 \cdot 6$ & $22 \cdot 3$ \\
\hline$I \cdot 25$ & I9 & 19 & $77 \cdot 8$ & 70.0 & $35 \cdot 7$ \\
\hline
\end{tabular}

\section{Esters of sulphonic acids and other trichloro-derivatives}

Two main series of compounds were studied, derivatives of methane sulphonic acid and of trichloromethane sulphonic acid. The results are given in Table 7 , with the results of tests with the ester of an aromatic sulphonic acid (tosylate) and the only ester of an aromatic carboxylic acid tested, benzoic acid.

Methane sulphonic acid (neutralized) was not inhibitory, but its TCE ester was a potent inhibitor. There were difficulties in characterizing this and other sulphonic acid esters, because they tended to decompose during GLC. However, the TLC showed, albeit less accurate, that contamination with alcohol was less than $5 \%$.

Trichloromethane sulphonic acid was a very weak inhibitor and its esters with TCE and ethanol were moderately active inhibitors. Thus, there was an analogy with the esters of TCA. TCE trichloromethane sulphonate was more active than the ethyl ester, presumably because of hydrolysis and release of active TCE, but the ethyl ester, which on hydrolysis would release an inactive alcohol and a very weakly active acid, was nevertheless active and it must be assumed that the ester itself is an active inhibitor in this instance.

The esters of both the aromatic acids were good inhibitors, but not as potent as TCE-P. The trichloro-2-propanol was more active than trichloroacetone and unlike the esters of TCE, the ester of the trichloro $\mathrm{C}_{3}$ alcohol was less active than the constituent alcohol.

\section{Summary of results}

The relative inhibitory activities (RIA) of most of the compounds studied in these experiments are given in Table 7 where, in general, the higher the value the better the inhibitor. The values for RIA given in Table 7 were calculated from the equation, 
Table 7. Relative inhibitory activity $(R I A)$ of various compounds with respect to methane production during incubation of sheep rumen contents in vitro*

(The concentrations of the test compounds and of the trichloroethanol (TCE) ester of pivalic acid incubated at the same time and required to give $50 \%$ inhibition of methane production were used to calculate the RIA under standard conditions; RIA is the concentration of TCE pivalate divided by the concentration of the test compound and multiplied by 1000)

\begin{tabular}{|c|c|}
\hline Compound & RIA \\
\hline $\begin{array}{l}\text { Halogen-substituted ethanol } \\
\text { Monochloroethanol } \\
\text { Dichloroethanol } \\
\text { TCE } \\
\text { Trifluoroethanol } \\
\text { Tribromoethanol (TBE) }\end{array}$ & $\begin{array}{r}1 \\
22 \\
909 \\
0 \\
10000\end{array}$ \\
\hline $\begin{array}{l}\text { Esters of halogen-substituted } \\
\text { ethanols and pivalic acid } \\
\text { Monochloroethyl pivalate } \\
\text { Dichloroethyl pivalate } \\
\text { TCE pivalate } \\
\text { Trifluoroethyl pivalate } \\
\text { TBE pivalate }\end{array}$ & $\begin{array}{r}0 \\
6 \\
1000 \\
1 \\
2500\end{array}$ \\
\hline $\begin{array}{l}\text { Esters of TCE and fatty acids } \\
\text { TCE acetate } \\
\text { TCE butyrate } \\
\text { TCE isobutyrate } \\
\text { TCE valerate } \\
\text { TCE isovalerate } \\
\text { TCE hexanoate } \\
\text { TCE isohexanoate } \\
\text { TCE palmitate } \\
\text { TCE versatate } \\
\text { TCE linolenate }\end{array}$ & $\begin{array}{r}500 \\
909 \\
833 \\
1250 \\
1000 \\
1250 \\
625 \\
278 \\
217 \\
51\end{array}$ \\
\hline $\begin{array}{l}\text { Esters of dibasic acids } \\
\text { TCE succinate } \\
\text { TCE glutarate } \\
\text { TCE adipate } \\
\text { TBE succinate } \\
\text { TBE adipate } \\
\text { Isobutyl adipate }\end{array}$ & $\begin{array}{r}1000 \\
1667 \\
1428 \\
5000 \\
2500 \\
13\end{array}$ \\
\hline
\end{tabular}

\begin{tabular}{|c|c|}
\hline \multirow{2}{*}{$\begin{array}{l}\text { Compound } \\
\text { Esters of trichoroacetic acid } \\
\text { (TCA) }\end{array}$} & RIA \\
\hline & \\
\hline TCA & 4 \\
\hline TCE TCA & 714 \\
\hline Ethyl TCA & 17 \\
\hline Isobutyl TCA & 21 \\
\hline t-Butyl TCA & 96 \\
\hline Isobutyl isobutyrate & I \\
\hline Isobutyraldehyde & I \\
\hline$n$-Pentyl TCA & 8 \\
\hline Amyl TCA & I4 \\
\hline Neopentyl TCA & 23 \\
\hline 2,5-Hexanediol TCA & 43 \\
\hline 1,6-Hexanediol TCA & 8 \\
\hline Esters of sulphonic acids & \\
\hline Methane sulphonic acid & $\circ$ \\
\hline TCE methane sulphonate & $5^{88}$ \\
\hline Trichloromethane & \\
\hline sulphonic acid & 9 \\
\hline $\begin{array}{l}\text { TCE trichloromethane } \\
\text { sulphonate }\end{array}$ & \\
\hline Ethyl trichloromethane & \\
\hline sulphonate & 64 \\
\hline TCE tosylate & 294 \\
\hline Trichloro $\mathrm{C}_{3}$ compounds & \\
\hline Trichloroacetone & 340 \\
\hline Trichloro-2-propanol & 454 \\
\hline Trichloro-2-propanol & \\
\hline pivalate & 214 \\
\hline General & \\
\hline Chloral hydrate & 526 \\
\hline TCA & 714 \\
\hline TCE benzoate & \\
\hline
\end{tabular}

* For details of experimental procedure, see pp. 430-r.

$\mathrm{RIA}=(\mathrm{C} / \mathrm{T}) \times 100$, where $\mathrm{C}$ and $\mathrm{T}$ are the concentrations of TCE-P and the test compound respectively, which have $50 \%$ inhibition of methane production, when incubated at the same time. The positive control (TCE-P) has a value of rooo on this scale. The assessment of the inhibitors might be as follows: < I0 non-inhibitors, Io-100 poor, 100-500 moderate, 500-I 500 good, > I 500 excellent.

\section{DISCUSSION}

Experiments with halogen-substituted alcohols and their esters have shown that the number and type of halogen atoms were of considerable importance for inhibition of methane production. The monochloro and the trifluoro compounds were virtually non-inhibitory. 'The dichloro compounds were relatively weak inhibitors; the alcohol 
Table 8. Comparison of inhibitory activity of various trichloro-substituted compounds with respect to methane production during incubation of sheep rumen contents in vitro*

\begin{tabular}{|c|c|c|c|}
\hline & \multicolumn{3}{|c|}{ Concentration to give $5 \circ \%$ inhibition $(\mu \mathrm{mol} / 1)$} \\
\hline Compound & $\begin{array}{l}\text { Individual } \\
\text { estimations }\end{array}$ & $\begin{array}{l}\text { Comparative } \\
\text { experiment } \dagger\end{array}$ & $\begin{array}{c}\text { Literature } \\
\text { values }\end{array}$ \\
\hline drate & 63 & 23.9 & I40f \\
\hline cetic acid (TCA) & 3300 & 3010.0 & $800 \S$ \\
\hline thanol (TCE) & 40 & $21 \cdot 3$ & - \\
\hline late & $\begin{array}{l}35 \\
8 \cdot I\end{array}$ & $12 \cdot 8$ & - 8.of \\
\hline cetamide & 17 & $\longrightarrow$ & $12 \cdot 0 \$$ \\
\hline $\mathrm{CA}$ & 344 & - & - \\
\hline & 22 & - & - \\
\hline & 27 & $\longrightarrow$ & - \\
\hline
\end{tabular}

* For details of experimental procedure, see pp. 430-r.

$\uparrow$ All compounds were tested concurrently, using concentrations that would give about $50 \%$ inhibition.

I Prins, Van Nevel \& Demeyer (I972).

$\$$ Trei, Parish, Singh \& Scott (1971).

was three to four times more active as an inhibitor than the ester. The tribromoethyl alcohol and its pivalate ester were the most potent inhibitors tested and again the alcohol was about four times more effective than the ester. Subsequent work with the trichloro derivatives of propan-2-ol also showed that the ester was less potent than the alcohol or ketone. On the other hand, numerous experiments with TCE and its pivalate ester showed that this alcohol and its ester had about the same activity. This property was shared by the esters of other $\mathrm{C}_{5}$ acids, and to a certain extent by the esters of $\mathrm{C}_{4}$ and $\mathrm{C}_{6}$ acids, but not those of $\mathrm{C}_{16}$ and $\mathrm{C}_{10}$ branched-chain acids.

The solubility of TCE-P was low $(32 \mathrm{mg} / \mathrm{l})$ and the ester was hydrolysed slowly. It is unlikely that the similarity in inhibitory activities of this ester and its constituent alcohol would be due to a very rapid hydrolysis. It is more likely that the ester is taken up intact by bacteria and that its ability to enter the microbial cell is a function of its structure. It is interesting to consider the inductive effects of the two ends of the molecule. The alcohol has three chlorine atoms on one $\mathrm{C}$ atom, which is one of the most electron-attracting groups known, and the acid has the most electronreleasing group $\left(\left(\mathrm{CH}_{3}\right)_{3} \mathrm{C}\right)$. Yet this might not be the basic property that governs the activity of these compounds because valeryl and isovaleryl residues in TCE esters did not result in the inhibitors being less efficient than the pivalate.

There is much evidence that the methyl derivative of vitamin $B_{12}$ is an intermediate in the production of methane. The accepted pathways involve the transfer of a methyl group from 5 -N-methyltetrahydrofolic acid to the reduced vitamin $B_{12}$ and the liberation of methane from methyl vitamin $\mathrm{B}_{12}$ in the presence of an electron donor system in which ferrodoxin has been implicated. It was shown by Hogenkamp (1965) that methyl vitamin $\mathrm{B}_{12}$ can be photolysed, but the products of the reaction are different depending on whether oxygen is in excess or in restricted supply. In the presence of excess oxygen the products are aquocobalamin and formaldehyde, but with traces of 
oxygen the products are reduced vitamin $\mathrm{B}_{12}$, methane, ethane and formaldehyde. Brot, Taylor \& Weissbach (I966) maintained that methyl transfer from 5-N-methyltetrahydrofolic acid involves enzyme-bound cobalamin, while the methyl transfer from methyl vitamin $B_{12}$ (and possibly methane production) does not involve enzyme-bound cobalamin. On the other hand, Wood \& Wolfe (I966) showed that the cobalamin enzyme involved in methane formation could be inactivated by propylation and reactivated by photolysis. Wood et al. (1968) prepared several halogenated cobalamin derivatives, including methyl chloride, methylene chloride, chloroform and carbon tetrachloride. They showed that the photolytic cleavage of the dichloromethyl ligand was not analogous with the cleavage of the methyl ligand and that one product with the dichloromethyl ligand was a reactive chlorocarbene. The over-all reaction appears to be:

$$
\stackrel{{ }^{\mathrm{CHCl}}}{\mathrm{Co}_{2}}+\mathrm{I}_{5} \mathrm{H}_{2} \rightarrow>\mathrm{Co}<+\mathrm{CH}_{3} \mathrm{Cl}+\mathrm{HCl} \text {, }
$$

where $>\mathrm{Co}<$ is cobalamin. It was also suggested that the formation of the polyhalogen ligands takes place according to the reaction:

$$
>\mathrm{Co}<+\mathrm{CX}_{n} \mathrm{H}_{m} \rightarrow>\text { Co }<X^{-},
$$

where $n$ is $\mathrm{I}, 2,3$ or $4, n+m=4, X$ is the halogen and the cobalamin (> Co $<$ ) is in a reduced monovalent state.

Bauchop ( 1967 ) found that chloroform and related compounds inhibited methane production in the rumen. Wood et al. (1968), using an in vitro system, found that these polyhalogen compounds inhibited methane production competitively. The inhibited system could be reactivated by photolysis, but reactivation was less with chloroform than with dichloride and the authors suggest that the formation of reactive free radicals and their addition to the corrin nucleus or to an amino acid close to the catalytic site could interfere strongly with enzyme action. Prins (1965) incubated rumen contents with chloral hydrate at $2.5 \mathrm{mmol} / \mathrm{l}$ and concluded that chloral hydrate was partly converted to TCE and partly decomposed to chloroform and formic acid. No measurements of methane production were made, but the trichloro derivative caused an increase in the propionic acid:acetic acid ratio and a change from Gramnegative to Gram-positive microflora. It is known that when chloral is heated with concentrated alkali, chloroform and formic acid are produced but there is little evidence that these products may be found under physiological conditions.

TCA is a weak inhibitor but it is not known whether this is because it is too stable to be dissimilated into active products or because it cannot enter the cells. If the latter is accepted, then it must be assumed that the cells are permeable to the esters of TCA and that the acid becomes inhibitory once inside the cell, either directly, or after conversion to chloral and chloroform.

Like other TCA esters, neopentyl TCA is a more potent inhibitor than either of its hydrolysis products. This suggests that the structure of the microbial cell surface 
is such that the cells are permeable to this compound. Neopentyl TCA and its isomer TCE-P have very similar structures and if we accept that the former can enter the cell without previous hydrolysis, the cells should be permeable to the latter. However, the nature of the actual inhibitory compound remains uncertain. Some individual and comparative results of inhibitory activity of various related compounds are given in Table 8. Clearly, chloroform appears to be the most active compound, whereas TCE and TCE-P, although weaker than chloroform, are better inhibitors than chloral hydrate and much better than TCA. When small amounts of TCA, TCE or chloral hydrate were heated with conc. sodium hydroxide, only chloral hydrate was converted to chloroform. TCA did not change and although TCE reacted to give a brown product there was no chloroform. If similar reactions take place under physiological conditions, and if chloroform is the actual inhibitor, then one would have to assume that both TCE and TCA or their esters would have to be converted to chloral and then to chloroform, before inhibition would ensue. Yet chloral hydrate does not appear to be a better inhibitor than TCE or some of its esters. It is possible that the reactive substance is chloral rather than the hydrate and that chloral hydrate cannot enter the cells as readily as the alcohol or some of its esters. The conversion to the alcohol and oxidation to the aldehyde would then take place inside the cell.

\section{REFERENCES}

Bauchop, T. (1967). F. Bact. 94, i7x.

Blaxter, K. L. \& Czerkawski, J. W. (r966). F. Sci. Fd Agric. 17, 4 ×7.

Brot, N., Taylor, R. \& Weissbach, H. (1966). Archs Biochem. Biophys. I14, 256.

Clapperton, J. L. \& Czerkawski, J. W. (197I). Br. F. Nutr. 26, 459.

Cottyn, B. G. \& Boucque, C. V. (1968). F. agric. Fd Chem. r6, I05.

Crane, A., Nelson, W. O. \& Brown, R. E. (1957). Y. Dairy Sci. 40, 1317.

Czerkawski, J. W. (1972). Proc. Nutr. Soc. 31, 141.

Czerkawski, J. W. (1973). Process Biochem. 8, 25.

Czerkawski, J. W., Blaxter, K. L. \& Wainman, F. W. (1966). Br. F. Nutr. 20, 349.

Czerkawski, J. W. \& Breckenridge, G. (1970). Lab. Pract. 19, 717.

Czerkawski, J. W. \& Breckenridge, G. (1972). Br. F. Nutr. 27, 131.

Czerkawski, J. W. \& Breckenridge, G. (1973). Br. F. Nutr. 29, 317.

Czerkawski, J. W. \& Clapperton, J. L. (I 968). Lab. Pract. 17, 994.

Demeyer, D. I. \& Henderickx, H. K. (1967). Biochim. biophys. Acta r37, 484.

Henderson, C. (1973). \%. agric. Sci., Camb. 81, 107.

Hogenkamp, H. P. C. (I965). Biochemistry, Easton 5, 417.

Johnson, D. E. (1972). F. Anim. Sci. 35, 1064.

Johnson, D. E., Wood, A. S., Store, J. B. \& Morgan, E. T. (1972). Can. F. Anim. Sci. 52, 703.

McBride, B. C. \& Wolfe, R. S. (I97I). Nature, Lond. 234, 55 I.

Marty, R. J. \& Demeyer, D. I. (1973). Br. F. Nutr. 30, 369 .

Noordam, M. A., Manten, A. \& Muller, F. M. (1949). Antonie van Leeuwenhoek 15, 65.

Prins, R. A. (1965). F. Dairy Sci. 48, 99 I.

Prins, R. A., Van Nevel, C. J. \& Demeyer, D. I. (1972). Antonie van Leeuwenhoek 38, 28 I.

Rufener, W. H. Jr \& Wolin, M. J. (1968). Appl. Microbiol. 16, 1955.

Sawyer, M. S., Hoover, W. H. \& Sniffen, C. J. (1974). J. Anim. Sci. 38, 908.

Singh, Y. K. \& Trei, J. E. (1971). Fedn Proc. Fedn Am. Socs exp. Biol. 30, 404 Abstr.

Trei, J. E., Parish, R. C., Singh, Y. K. \& Scott, G. C. (I 97I). F. Dairy Sci. 54, 536.

Trei, J. E., Scott, G. C. \& Parish, R. C. (1972). F. Anim. Sci. 34, 510.

Van Nevel, C. J., Henderickx, H. K., Demeyer, D. I. \& Martin, J. (1969). Appl. Microbiol. 17, 695.

Wolin, E. A., Wolfe, R. S. \& Wolin, M. J. (1964). F. Bact. 87, 993.

Wood, J. M., Kennedy, F. S. \& Wolfe, R. S. (r968). Biochemistry, Easton 7, 1707.

Wood, J. M. \& Wolfe, R. S. (I966). Biochemistry, Easton 5, 3598. 